\title{
Cervical Characterization with Tactile-Ultrasound Probe
}

\author{
Vladimir Egorov ${ }^{1}$, Todd Rosen ${ }^{2}$, Heather van Raalte ${ }^{3}$, Viktors Kurtenoks ${ }^{1}$ \\ ${ }^{1}$ Advanced Tactile Imaging, Trenton, NJ, USA \\ ${ }^{2}$ Department of Obstetrics, Rutgers Robert Wood Johnson Medical School, New Brunswick, NJ, USA \\ ${ }^{3}$ Princeton Urogynecology, Princeton, NJ, USA \\ Email: egorov@tactile-imaging.com,vegorov@artannlabs.com
}

How to cite this paper: Egorov, V., Rosen, T., van Raalte, H. and Kurtenoks, V. (2020) Cervical Characterization with TactileUltrasound Probe. Open Journal of Obstetrics and Gynecology, 10, 85-99. https://doi.org/10.4236/ojog.2020.101008

Received: December 16, 2019

Accepted: January 5, 2020

Published: January 8, 2020

Copyright (c) 2020 by author(s) and Scientific Research Publishing Inc. This work is licensed under the Creative Commons Attribution International License (CC BY 4.0).

http://creativecommons.org/licenses/by/4.0/

\begin{abstract}
Background: Premature cervical softening and shortening may be considered an early mechanical failure that predisposes to preterm birth. Preliminary clinical studies demonstrate that cervical elastography may be able to quantify this phenomenon and predict spontaneous preterm delivery. Objective: To explore a new approach for cervix elasticity and length measurements with tactile-ultrasound probe. Methods: Cervix probe has tactile array and ultrasound transducer designed to apply controllable load to cervix and acquire stress-strain data for calculation of cervical elasticity (Young's modulus) and cervical length for four cervix sectors. Average values, standard deviations, intraclass correlation coefficients and the $95 \%$ limits of agreement (Bland-Altman plots) were estimated. Results: Ten non-pregnant and ten pregnant women were examined with the probe. The study with non-pregnant women demonstrated a reliable acquisition of the tactile signals. The ultrasound signals had a prolonged appearance; identification of the internal os of the cervix in these signals was not reliable. The study with pregnant women with the gestational age of $25.4 \pm 2.3$ weeks demonstrated reliable data acquisition with real-time visualization of the ultrasound signals. Average values for cervical elasticity and standard deviations of $19.7 \pm 15.4 \mathrm{kPa}$ and length of $30.7 \pm 6.6 \mathrm{~mm}$ were calculated based on two measurements per 4 sectors. Measurement repeatability calculated as intraclass correlation coefficients between two measurements at the same cervix sector on pregnant women was found to be 0.97 for cervical elasticity and 0.93 for the cervical length. The $95 \%$ limits of agreement of 1) cervical elasticity were from $-22.4 \%$ to $+14.9 \%$, and 2) cervical length from $-13.3 \%$ to $+16.5 \%$. Conclusions: This study demonstrated clinically acceptable measurement performance and reproducibility. The availability of stress-strain data allowed the computation of cervical elasticity and length. This approach has the potential to provide cervical markers to predict spontaneous preterm delivery.
\end{abstract}




\section{Keywords}

Cervical Elasticity, Cervical Length, Tactile, Ultrasound, Elastography, Premature Cervical Softening, Spontaneous Preterm Delivery

\section{Introduction}

Preterm delivery is a leading cause of infant mortality and morbidity. It is estimated that annually about 15 million infants are born preterm worldwide [1]. Across 184 countries, the rate of preterm birth ranges from 5\% to $18 \%$, with almost 1 million children dying each year due to complications in preterm birth. Of the 14 million survivors per year, many face a lifetime of disability, including learning disorders, as well as visual and hearing impairments [2]. Long-term complications include cognitive disorders, behavioral problems, and cerebral palsy [3] [4] [5] [6]. These consequences imply devastating financial, social, and emotional effects on the parents and/or the affected children. In the US, the short-term hospital costs during the first year of life of preterm birth/low-birth-weight infants were estimated to be at $\$ 5.8$ billion and the estimated annual societal economic burden in the US is, at a minimum, $\$ 26.2$ billion [7]. Identifying women at risk for spontaneous preterm delivery (SPTD) remains an issue of paramount importance [8] [9] [10].

Premature cervical softening and shortening may be considered an early mechanical failure that predisposes to preterm birth [11]. The digital cervical score [12] and Bishop score [13] as predictors of SPTD have demonstrated low diagnostic accuracy (61\% - 68\%) [14]. Even though numerous risk factors associated with SPTD have been identified in previous work, the ability to accurately predict when labor will occur remains elusive [15] [16] [17] [18]. In a well-regarded, large observational cohort study, serial transvaginal ultrasound cervical length and quantitative vaginal fetal fibronectin had low predictive accuracy for SPTD among nulliparous women [19]. Recent clinical findings suggest that cervical elastography may be a more useful test to predict preterm delivery [20]-[25]. Cervical elasticity may better assess microstructural changes in the cervix that predict preterm birth [26], and therefore, using cervical stiffness and length as part of a multiple marker screen to predict SPTD has the potential to improve on current methods.

The objective of this study was to assess a new approach for cervical elasticity and length measurements based on the acquisition of stress-strain data by a cervix probe with tactile and ultrasound transducers in a clinical study.

The pilot study was conducted with the use of a new cervical probe.

\section{Material and Methods}

\subsection{Study Design}

Between July 2017 and February 2018, 10 non-pregnant women and 10 pregnant 
women at 22 - 29 weeks of pregnancy were enrolled into a pilot clinical study and examined with the Cervix Monitor (CM). Written informed consent was obtained for this Institutional Review Board approved observational study (clinical trials identifiers NCT03199079). The study objectives were: 1) to assess the device performance, 2) to assess the potential risks of the CM to pregnant women and fetuses, first with non-pregnant women followed by pregnant subjects, and 3) to verify the proposed data collection and examination techniques. The study with pregnant women followed the assessment of the risks of the CM examination procedure with non-pregnant women, as required by the Code of Federal Regulations, Title 45, \$46.204(a). The inclusion criteria were that the participants had to be adult women, aged between 21 - 44 years, who were not pregnant for the first phase of the study, and pregnant in the second phase. Exclusion criteria included the presence of active cancer of the colon, rectum wall, cervix, vagina, uterus or bladder; ongoing or prior radiation therapy for abdominal or pelvic cancer; recent (less than 12 months) pelvic surgery; surgically absent uterus, rectum or bladder; significant circulatory or cardiac conditions that could cause excessive risk from the examination as determined by the attending physician; severe abdominal or pelvic adhesions preventing access to pertinent anatomy; known or suspected bleeding disorders; HIV or hepatitis B positive serology; warty lesions on the vulva; extensive varicose veins on the vulva; active skin infection or ulceration within the vagina/vulva (Herpes infection); and the presence of a vaginal septum. In addition, pregnant women deemed to be at a high-risk owing to a maternal or fetal condition were excluded. The participants' age, height, weight, gestational age and parity distribution data were collected. The total study workflow comprised of the following steps: 1) Recruiting women who routinely undergo gynecological or obstetric examination; 2) Acquisition of clinical information related to the studied cases by standard clinical means; 3) Performing a CM examination in a lithotomy position; and 4) Analyzing the CM data. All the participating women were asked to complete a questionnaire about their pain and comfort levels during the CM examination.

\subsection{Cervix Monitor (CM)}

The Vaginal Tactile Imager (VTI) was initially developed as a biomechanical mapping device to assess vaginal and pelvic floor conditions [27] [28]. It allows the acquisition of cervical pressure response signals but does not allow cervical elasticity and length measurements. The CM has a drastically revised design in most of the engineering and clinical aspects.

The CM was designed as a cart-based device with a medical grade touchscreen computer (Tangent, CA) and a detachable single-use cervix probe. The CM probe contains a tactile array with four sensors and an ultrasound transducer as shown in Figure 1. The ultrasound $3.0 \mathrm{MHz}$ transducer, working in the pulse-echo mode with data acquisition resolution of $20 \mathrm{~ns}$ ( $50 \mathrm{MHz}$ sample rate), measures $3.5 \mathrm{~mm}$ in diameter. Biocompatible, two-component silicones (NuSil 
A

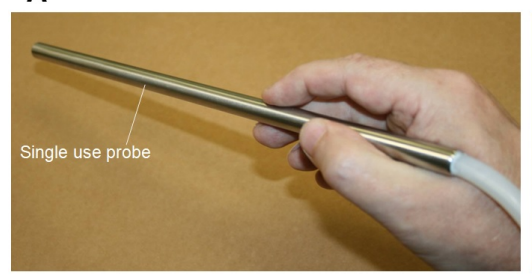

B

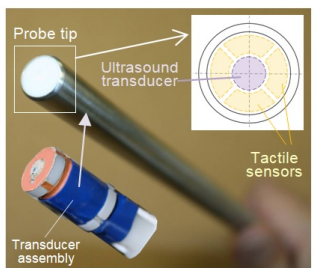

C

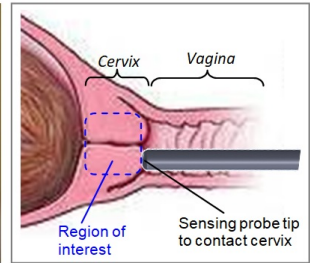

Figure 1. Cervical probe. (A) General view of the Cervix Monitor probe; (B) Probe tip with tactile and ultrasound transducers; (C) Probe positioning at cervical measurement.

Technology, CA) were employed to provide sensor assembly functionality, durability, stability and mechanical protection. A proprietary printed circuit board was designed to perform the dual functions of tactile signal acquisition and generation/acquisition of synchronized ultrasound signals. Its key features are to serve four tactile/pressure sensors and one ultrasound transducer at 100 data frames per second. Figure 1 presents the CM probe used in this study.

The pressure measurement noise level was below $25 \mathrm{~Pa}$ within the operational range of $40 \mathrm{kPa}$. The ultrasound transmitting pulses had a peak amplitude below $50 \mathrm{~V}$, a length less than $1 \mu \mathrm{s}$, which provide acoustic power significantly below the limits established by the FDA for ultrasound emission in obstetrics: spatial-peak temporal-average Ispta $=94\left(\mathrm{~mW} / \mathrm{cm}^{2}\right)$, spatial-peak pulse-average intensity Isppa $=190\left(\mathrm{~W} / \mathrm{cm}^{2}\right)$, and mechanical index MI $=1.9$. Medical grade 316 stainless steel, used in the production of surgical instruments, was used to fabricate the probe body (Figure 1). The CM software interface allows real-time observation of the cervical ultrasound signal as well as applied pressure. The ultrasound peak position for cervix internal os signal was calculated with the use of a signal envelope after the Gaussian complex wavelet filtering [29] at $3 \mathrm{MHz}$ frequency. The cervical elasticity was calculated as a ratio of the applied load (stress) to the surface of the cervix from the CM probe to the resultant changes of the cervical length (strain). This approach was validated with the soft tissue models in bench testing and verification. Young's modulus was calculated from the stress-strain data based on a semi-infinitive linear elastic model [30] [31].

\subsection{Examination Procedure}

The CM examination procedures followed the following steps: 1) Inserting the speculum into the vagina to provide appropriate visualization and access to the cervix; 2) Performing double CM measurements at 3, 6, 9, and 12 o'clock, specifying the probe tip location on cervix on the CM touchscreen display; 3 ) Reviewing of the measurement results (ultrasound reflected waves and applied loads); and 4) Removal of the probe and speculum from the vagina.

\subsection{Statistical Analysis}

Measurement repeatability between two measurements at the same cervix sector on pregnant women was assessed with an intraclass correlation coefficient (ICC), as the correlation between any two measurements made on the same 
subject [32]. The following parameters were calculated as described by Bland and Altman [33]: 1) Bias (i.e., the mean of the proportionate difference [the difference between two CM measurements divided by the average value of two measurements]); 2) Precision (i.e., the standard deviation of the difference between the two measurements); and 3) Proportionate 95\% limits of agreement (i.e., 1.96 times the standard deviation of the mean of the proportionate difference). The average values and standard deviations were calculated. Statistical analysis was performed with MATLAB version R2018a (MathWorks, MA).

\section{Results}

\subsection{Study with Non-Pregnant Women}

The study with non-pregnant women demonstrated reliable acquisition of the tactile signals. However, the ultrasound reflected signals had prolonged appearance; identification of the cervix internal os in these signals was not reliable. However, the signal post-processing of 8 of the 10 cases allowed the calculation of average cervical elasticity of $54 \pm 17 \mathrm{kPa}$ and length of $42 \pm 13 \mathrm{~mm}$. In 2 of the 10 cases, we found very low returned ultrasound signal amplitudes which offered no possibility for the elasticity assessment. These were expected difficulties with $\mathrm{CM}$ signal acquisition due to the cervical anatomy and positioning in non-pregnant women. The average pain level for 10 cases was 1.1 on the scale from 1 to 4 (1: none, 2: mildly painful, 3: painful, 4 : severely painful). The comfort level was adjudged at 2.2 on the scale from 1 to 3 , i.e. essentially similar to manual palpation (1: more comfortable than manual palpation, 2: the same, 3 : less comfortable).

\subsection{Study with Pregnant Women}

Women at $22-29$ weeks of pregnancy scheduled for a regular examination were considered eligible for the second part of the CM study enrollment. CM measurements were performed at an average gestational age of $25.4 \pm 2.3$ weeks (range, 22 - 29 weeks). The study of all ten women was successful. The recorded ultrasound signals had an identifiable peak amplitude reflected from the cervix's internal os to allow reproducible measurement of ultrasound time-of-flight (see Figure 2). The peak position was calculated with the use of a signal envelope-see the light brown envelope line in the left panel of Figure 2.

Figure 3 presents all CM data recorded for cases 1 - 10. The cervix map has four sectors; the results for one of ten cases (tissue elasticity and length distribution per four sectors) are shown in Figure 3. Average values and standard deviations (up/down bars) for cervical elasticity and length for 10 cases were calculated based on two measurements per 4 sectors ( 8 measurements per case); the values were $19.7 \pm 15.4 \mathrm{kPa}$, and the length was $30.7 \pm 6.6 \mathrm{~mm}$. The average standard deviation for the 4 cervix sector measurements of elasticity was found as $\pm 3.5 \mathrm{kPa}$ and the length was $\pm 3.4 \mathrm{~mm}$.

Measurement repeatability between two measurements at the same cervix 
A

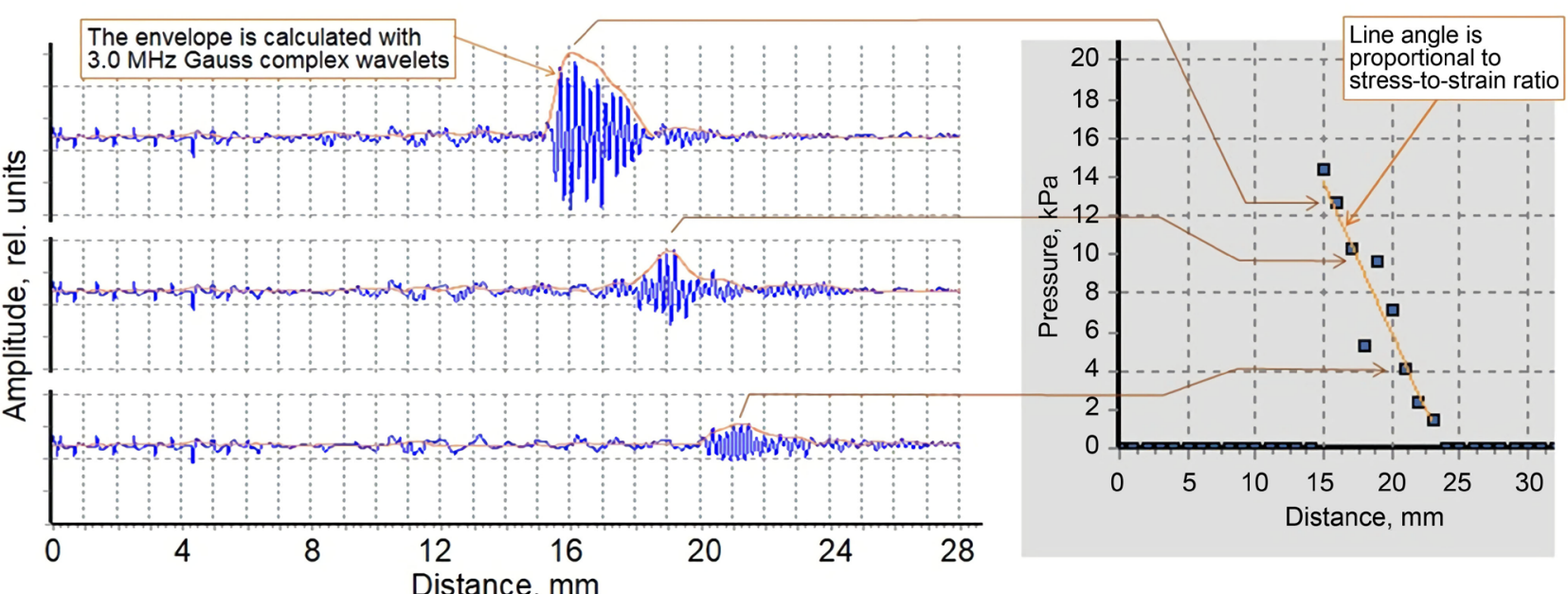

Figure 2. Measurement approach. (A) Ultrasound signals reflected from internal cervical os during cervix deformation by the probe; (B) Stress (pressure)-strain (compression) data recorded for 32 y.o. women at 25 week pregnancy.

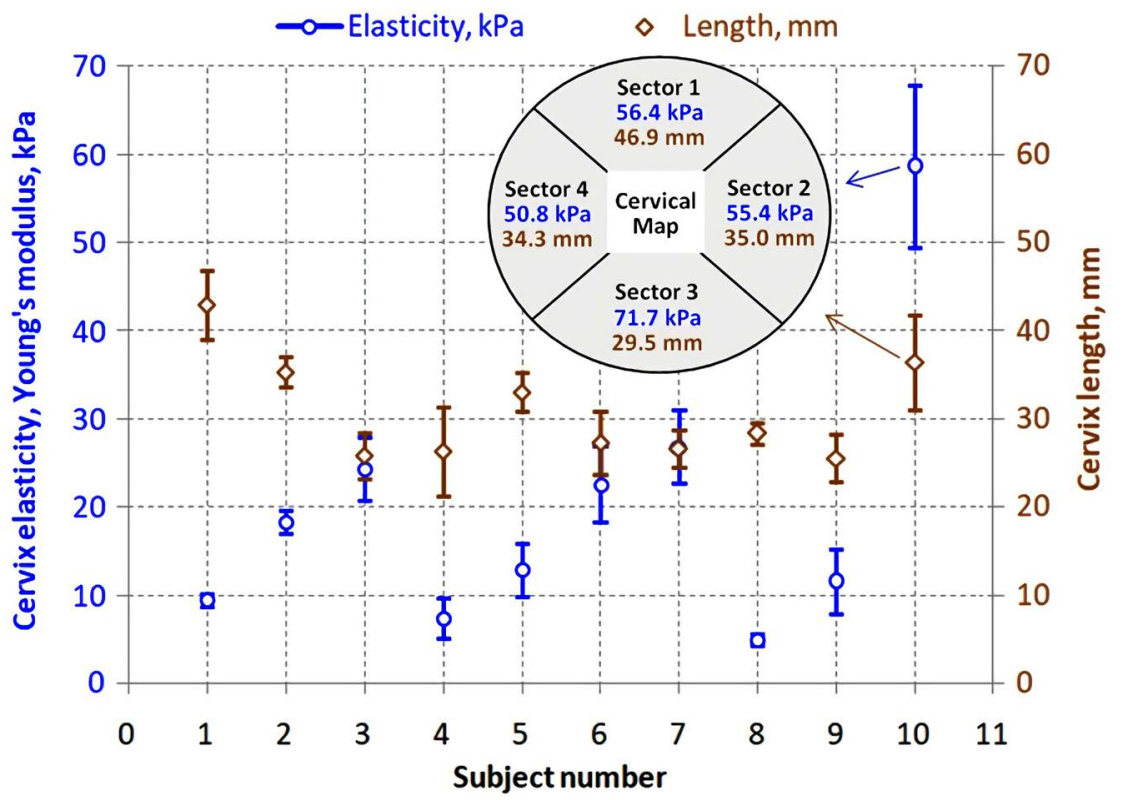

Figure 3. Cervical elasticity and length for 10 pregnant women measured by Cervix Monitor. Cervical Map with four sectors shows measurement results for subject number 10 .

sector on pregnant women was assessed with an intraclass correlation coefficient (ICC), as the correlation between any two measurements made on the same subject [34]. ICC for cervix elasticity was found to be 0.97 and for a cervical length of 0.93 (see Figure 4). The bias and the $95 \%$ limits of agreement of the cervical elasticity measurement are $3.8 \%$ and $-22.4 \%$ to $+14.9 \%$, the precision was $9.5 \%$ (see left panel in Figure 5). The bias and the $95 \%$ limits of agreement of the cervical length measurements are $-1.6 \%$ and $-13.3 \%$ to $+16.5 \%$, the precision was $7.6 \%$ (see right panel in Figure 5). 
A

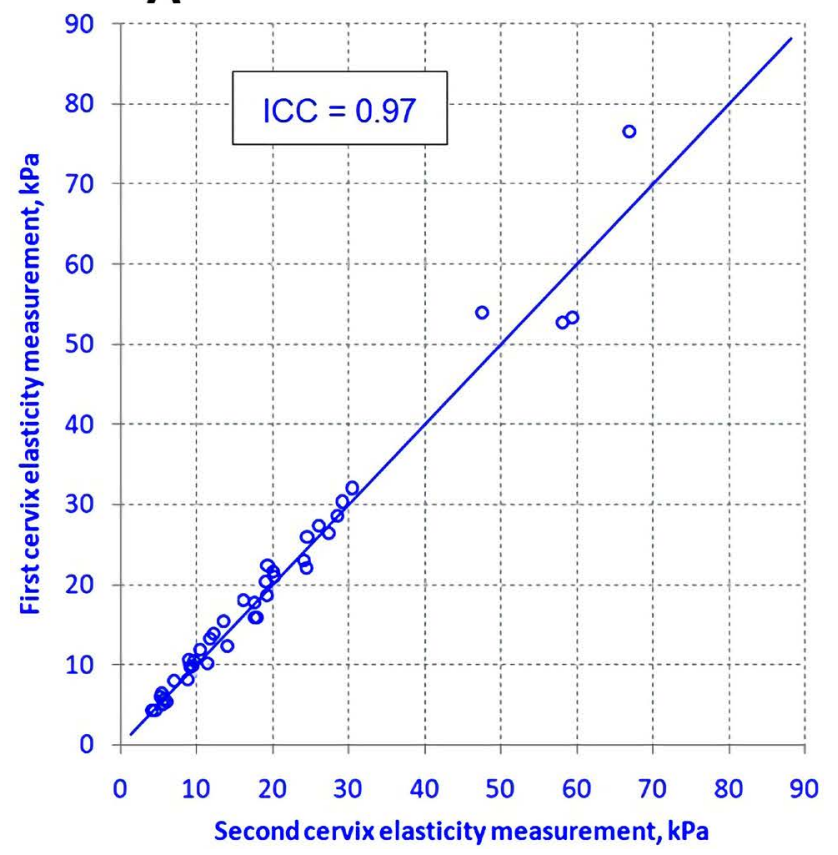

B

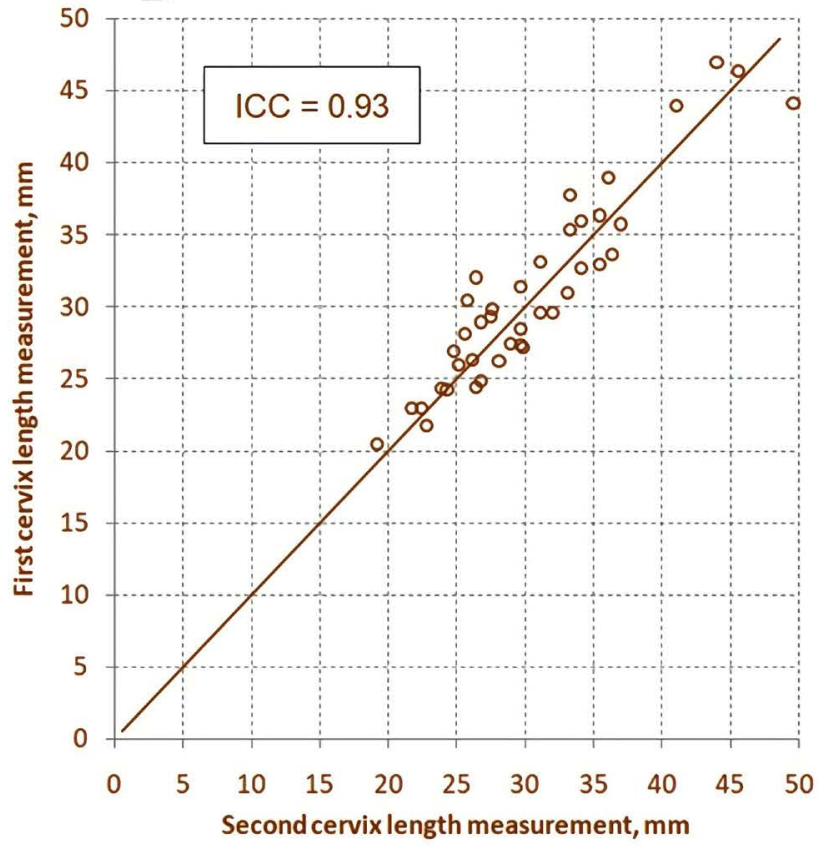

Figure 4. Relationship for two measurements. Intraclass correlation coefficients (ICC) for two measurements of cervical elasticity (A) and length (B) by the same operator.

A

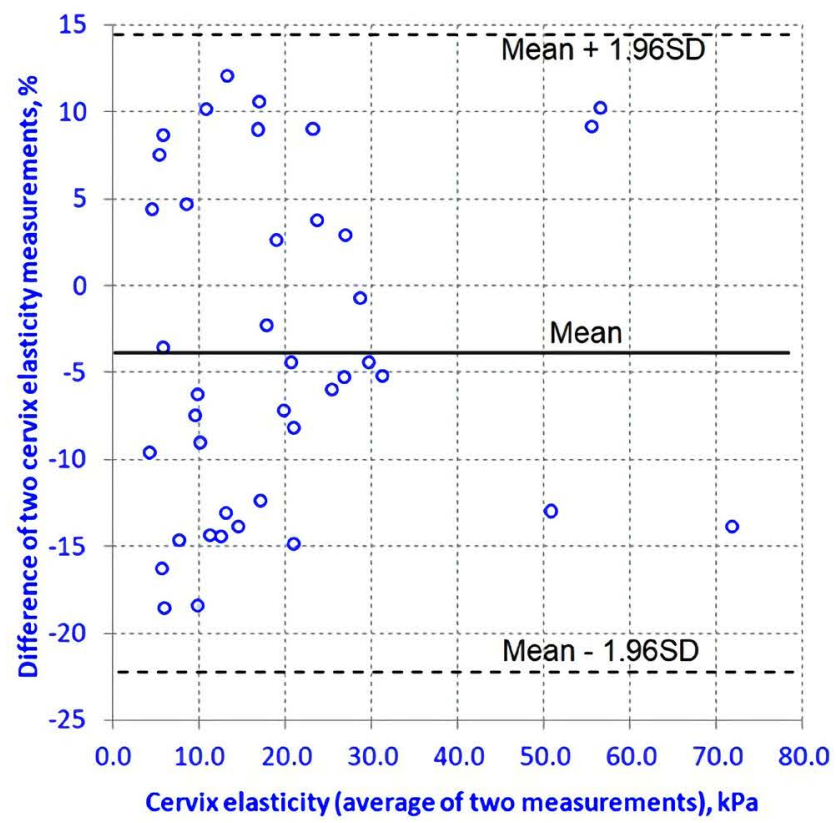

B

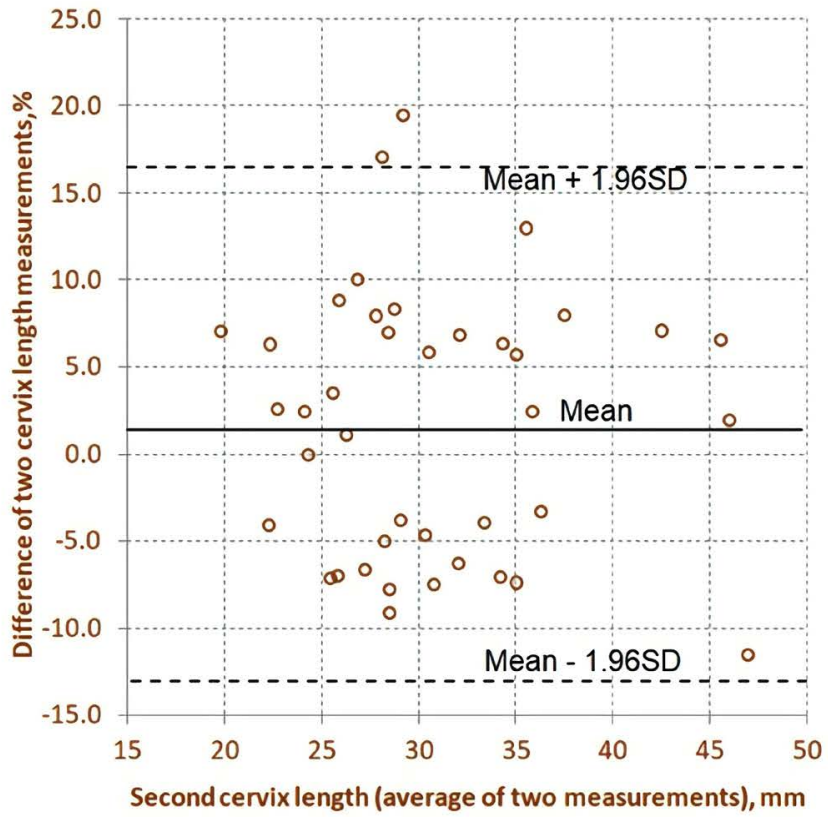

Figure 5. Scatter plots of difference between two measurements. Bland-Altman scatter plot of the percentage difference between two measurements of cervical elasticity (A) and length (B) by the same operator. The solid lines represent the proportionate mean difference; the dashed lines represent the $95 \%$ limits of agreement.

The cervical length measurements with GE Voluson E8 (conventional ultrasound method) was not part of the protocol, but we obtained the measurements in 8 of 10 subjects that were studied. The Pearson correlation coefficient between 
cervical length measured with CM (average in sectors 1 and 3) and commercial ultrasound was found to be 0.48 for these 8 subjects; CM in average demonstrated $16.4 \%$ decrease versus conventional ultrasound in cervix length measurements.

The average level of pain reported by pregnant women was 1.7 on the scale from 1 to 4 ; the comfort level as 2.0 on a scale from 1 to 3 . No adverse events with the $\mathrm{CM}$ were reported.

\section{Discussion}

The study has shown that the proposed tactile-ultrasound approach allows the measurement of cervical elasticity and length at an average gestational age of $25.4 \pm 2.3$ weeks with an acceptable precision of $9.5 \%$ and $7.6 \%$ consequently. It seems that the acceptable measurement reproducibility with the soft tissue elasticity measurements, being transformed into the Young's module values, typically demonstrate a measurement accuracy of $3 \%-15 \%$ and a measurement repeatability of $8 \%-14 \%$ [31]. The cervical elasticity (average for 4 sectors) in this study ranged from $4.9 \mathrm{kPa}$ to $58.6 \mathrm{kPa}$ which constituted almost a 10 -fold change from the lowest value. The $9.5 \%$ change (precision) from $32 \mathrm{kPa}$ (average value in $4.9 \mathrm{kPa}-58.6 \mathrm{kPa}$ range) amounts to $3.0 \mathrm{kPa}$, seems to be an acceptable proportion for elasticity measurement. The length of the cervix (average for 4 sectors) in this study ranged from $25.5 \mathrm{~mm}$ to $42.9 \mathrm{~mm}$, which constitutes a $68 \%$ increase from the lower value. The critical changes in the cervical length are expected from $40 \mathrm{~mm}$ to $20 \mathrm{~mm}$ and $7.6 \%$ from the lower value will be $1.5 \mathrm{~mm}$. The average standard deviation for the 4 cervix sector measurements seems to basically represent the variability by the cervix sectors which were found as \pm 3.5 $\mathrm{kPa}$ (elasticity) and $\pm 3.4 \mathrm{~mm}$ (length). That means the reproducibility error of cervical length measurement of $\pm 1.5 \mathrm{~mm}$ is capable to detect not only the length differences in pregnant women, but it allows resolution of the cervix anatomical variability by its 4 sectors. The $+3.8 \%$ bias in the cervical elasticity measurement may be explained by the cervix strain hardening at the second measurement; the $-1.6 \%$ bias in the cervical length measurement may cause cervix strain hysteresis at the second measurement (see Figure 5).

$\mathrm{CM}$ appeared to under measure the cervix length in comparison with the conventional ultrasound. This may be explained by cervix lengthen during the cervical measurement with commercial ultrasound because funneling may lessen. In contrary, measurement with CM may shorten the cervix because CM probe is targeted to compress cervix along its canal. It may be advantageous to measure with CM only through a portion of the cervix (whether it is anterior, posterior or lateral) because funneling may be removed, which can be dynamic, from the equation. It is important to note that absolute cervical length is not important for the cervical elasticity measurement.

The average level of pain reported by women was 1.4 on the scale from 1 to 4 ; the comfort level as 2.1 on a scale from 1 to 3 . A speculum is generally consi- 
dered more uncomfortable that a manual digital exam; it is expected that the examination with the $\mathrm{CM}$ using the speculum was more uncomfortable.

In the last decade, a new technology named elastography, or elasticity imaging, for measuring and the visualizing the soft tissue viscoelastic characteristics, has emerged. Two approaches for cervical ultrasound elastography for quantitative determination of the physical properties of the cervix, namely, strain elastography and shear wave elastography have been developed. We identified 11 clinical studies in the last three years, which tested the hypothesis that cervical elastography may be useful in predicting preterm delivery [20]-[25] [34] [35] [36] [37] [38]. Of the eleven studies identified, seven used strain ultrasound [20]-[25] [35] and four used shear wave ultrasound [34] [36] [37] [38]. These studies assessed between 30 and 628 subjects with a total of 1901 women in the eleven studies. The data from these works suggest that assessment of cervical elasticity may be a more useful predictor than simply measuring the length of the cervix. Predictive sensitivity and specificity were found to be in the range from $59.0 \%$ and $86.0 \%$ [25] to $96.7 \%$ and $87.0 \%$ for the two approaches, respectively [37]. In all these publications, the investigators noted that they felt that significant additional work was necessary before the measurement procedure can be standardized and made reliable.

Strain ultrasound elastography determines only the relative values of tissue elasticity because the applied transducer pressure is unknown. The shear wave ultrasound elastography provides, in principle at least, a more objective description of tissue elasticity; however, the cervical elasticity is described as a shear wave speed [34] [36] [37] [38], but not as Young's modulus which requires solution of the inverse mechanical problem in absence of stress data. There are several difficulties in using this approach: 1) cervical tissue heterogeneity implies distortions in the shear wave elasticity estimates, 2) placing a transducer next to the cervix is likely to cause a tissue deformation, thereby causing a non-controllable increase in the tissue stiffening, 3) any movement should be avoided for 3 - 5 seconds with a shear wave transducer, and 4) it requires a special transducer [39]. Both these ultrasound techniques require premium level, expensive ultrasound equipment [40] [41]. A much simpler and a less expensive aspiration technique has significant limitations in the context of biomechanical characterization of the cervix: a) uncertainty of the applied force, and b) only a small volume of tissue, primarily on the distal cervix, is tested [11] [42]. The proposed approach with the CM allows a) direct acquisition of stress-strain data, and b) direct assessment of the cervix with Young's modulus [30] [31].

The clinical risk factors for SPTD include obstetric history (i.e., familial genetic predisposition, uterine malformation, previous preterm labor, previous cervical surgery) and other aspects of the current pregnancy (i.e., multifetal gestation, genital tract bleeding and/or infection, fetal malformation, shortened cervix) [43] [44]. Current tests for the SPTD can be divided into three general categories: 1) risk factors, 2) cervical conditions, and 3) biochemical testing. Combining all of the risk factors still falls short of $50 \%$ in the prediction of 
pregnancies that deliver preterm [43] [45]. The biochemical markers (gestation tissues, biological fluid analysis, proteomic data) for the prediction of SPTD do not achieve the desired diagnostic accuracy [46] [47] [48] [49] [50]. The cervical length, measured in the routine second-trimester transvaginal ultrasonography, is not sensitive enough to predict SPTD [19] [51] [52].

Extensive remodeling is needed for the cervix to dilate and pass a fetus completely. The extracellular matrix of the cervix is primarily made up of tightly packed collagen bundles. Gradually, throughout the pregnancy, the composition of the cervix changes as the collagen density decreases, and the realignment and degradation of collagen cross-linking due to proteolytic enzymes, and an increase in the hyaluronic acid and water content. Cervical softening and distention result from these extracellular matrix compositional changes [53].

This pilot study provided 1) the assessment of the proposed approach to measure cervix elasticity and length, 2) the highlights of its strong and weak aspects to be addressed in the probe and procedures modifications, and 3) the basis for extended prospective development and validation clinical studies.

The strength of this study lies in the novel approach for cervical elasticity and length. The cervical elasticity receives quantification in terms of Young's modulus from stress-strain data. We acknowledge that our study has some limitations. First, one needs to make sure that the reflected ultrasound signal came from the cervix internal oz; it will be the subject of further research. Second, it seems that a cervix elasticity model must be incorporated into the cervix elasticity calculation which will take in account the strain distribution along measured cervix compression (strain distribution) by the probe. Third, the total studies sample size in the study is relatively small. A study with a larger number of cases would enable us to explore the entire range of the cervical conditions and focus more on the prediction of SPTD at the gestational age when clinical procedures could prevent the SPTD. Yet, this is the first study using CM for this purpose, and the current study will serve as the basis to guide the design of future protocols.

The novelty of this work is the implementation of the tactile and ultrasound transducers in one cervical probe and demonstration of feasibility of proposed approach for measurement of cervical elasticity and length on pregnant women.

\section{Conclusion}

This study has demonstrated clinically acceptable measurement performance and reproducibility based on the acquisition of stress-strain data by tactile and ultrasound transducers. Availability of the stress-strain data allowed the computation of cervical elasticity and length. This approach has the potential to provide cervical markers in the prediction of spontaneous preterm delivery. Further research is needed.

\section{Acknowledgements}

Research grant R43HD090793 from Eunice Kennedy Shriver National Institute 
of Child Health \& Human Development (NICHD), USA. The content is solely the responsibility of the authors and does not necessarily represent the official views of the National Institutes of Health.

\section{Conflicts of Interest}

V. Egorov has submitted a patent application related to the described approach. The other authors declare no conflicts of interest regarding the publication of this paper.

\section{References}

[1] Chang, H.H., Larson, J., Blencowe, H., Spong, C.Y., Howson, C.P., Cairns-Smith, S., et al. (2013) Preventing Preterm Births: Analysis of Trends and Potential Reductions with Interventions in 39 Countries with Very High Human Development Index. The Lancet, 381, 223-234. https://doi.org/10.1016/S0140-6736(12)61856-X

[2] World Health Organization. Preterm Birth. http://www.who.int/en/news-room/fact-sheets/detail/preterm-birth

[3] Mwaniki, M.K., Atieno, M., Lawn, J.E. and Newton, C.R. (2012) Long-Term Neurodevelopmental Outcomes after Intrauterine and Neonatal Insults: A Systematic Review. The Lancet, 379, 445-452. https://doi.org/10.1016/S0140-6736(11)61577-8

[4] Parkinson, J.R., Hyde, M.J., Gale, C., Santhakumaran, S. and Modi, N. (2013) Preterm Birth and the Metabolic Syndrome in Adult Life: A Systematic Review and Meta-Analysis. Pediatrics, 131, e1240-1263. https://doi.org/10.1542/peds.2012-2177

[5] Li, S., Zhang, M., Tian, H., Liu, Z., Yin, X. and Xi, B. (2014) Preterm Birth and Risk of Type 1 and Type 2 Diabetes: Systematic Review and Meta-Analysis. Obesity Reviews, 15, 804-811. https://doi.org/10.1111/obr.12214

[6] Brehaut, J.C., Kohen, D.E., Garner, R.E., et al. (2009) Health among Caregivers of Children with Health Problems: Findings from a Canadian Population Based Study. American Journal of Public Health, 99, 1254-1262. https://doi.org/10.2105/AJPH.2007.129817

[7] Russell, R.B., Green, N.S., Steiner, C.A., et al. (2007) Cost of Hospitalization for Preterm and Low Birth Weight Infants in the United States. Pediatrics, 120, e1-e9. https://doi.org/10.1542/peds.2006-2386

[8] Campbel, S. (2018) Prevention of Spontaneous Preterm Birth: Universal Cervical Length Assessment and Vaginal Progesterone in Women with a Short Cervix: Time for Action! American Journal of Obstetrics \& Gynecology, 218, 151-158. https://doi.org/10.1016/j.ajog.2017.12.222

[9] Newnham, J.P., Dickinson, J.E., Hart, R.J., Pennell, C.E., Arrese, C.A. and Keelan, J.A. (2014) Strategies to Prevent Preterm Birth. Frontiers in Immunology, 19, 584. https://doi.org/10.3389/fimmu.2014.00584

[10] Blencowe, H., Cousens, S., Oestergaard, M.Z., Chou, D., Moller, A.B., Narwal, R., et al. (2012) National, Regional, and Worldwide Estimates of Preterm Birth Rates in the Year 2010 with Time Trends since 1990 for Selected Countries: A Systematic Analysis and Implications. The Lancet, 379, 2162-2172. https://doi.org/10.1016/S0140-6736(12)60820-4

[11] Myers, K.M., Feltovich, H., Mazza, E., Vink, J., Bajka, M., Wapner, R.J., Hall, T.J. and House, M. (2015) The Mechanical Role of the Cervix in Pregnancy. Journal of Biomechanics, 48, 1511-1523. https://doi.org/10.1016/j.jbiomech.2015.02.065 
[12] Houlton, M.C.C., Marivate, M. and Philpott, R.H. (1982) Factors Associated with Preterm Labour and Changes in the Cervix before Labour in Twin Pregnancy. BJOG: An International Journal of Obstetrics \& Gynaecology, 89, 190-194. https://doi.org/10.1111/j.1471-0528.1982.tb03611.x

[13] Bishop, E.H. (1964) Pelvic Scoring for Elective Induction. Obstetrics \& Gynecology, 24, 266-268.

https://journals.lww.com/greenjournal/Citation/1964/08000/Pelvic_Scoring_for_Ele ctive_Induction.18.aspx

[14] Newman, R.B., Goldenberg, R.L., Iams, J.D., Meis, P.J., Mercer, B.M., Moawad, A.H., Thom, E., Miodovnik, M., Caritis, S.N. and Dombrowski, M (2008) Preterm Prediction Study: Comparison of the Cervical Score and Bishop Score for Prediction of Spontaneous Preterm Delivery. Obstetrics \& Gynecology, 112, 508-515. https://doi.org/10.1097/AOG.0b013e3181842087

[15] Lucaroni, F., Morciano, L., Rizzo, G., D’Antonio, F., Buonuomo, E., Palombi, L. and Arduini, D. (2018) Biomarkers for Predicting Spontaneous Preterm Birth: An Umbrella Systematic Review. The Journal of Maternal-Fetal \& Neonatal Medicine, 31, 726-734. https://doi.org/10.1080/14767058.2017.1297404

[16] Son, M. and Miller, E.S. (2017) Predicting Preterm Birth: Cervical Length and Fetal Fibronectin. Seminars in Perinatology, 41, 445-451. https://doi.org/10.1053/j.semperi.2017.08.002

[17] Malouf, R. and Redshaw, M. (2017) Specialist Antenatal Clinics for Women at High Risk of Preterm Birth: A Systematic Review of Qualitative and Quantitative Research. BMC Pregnancy \& Childbirth, 17, 51. https://doi.org/10.1186/s12884-017-1232-9

[18] Georgiou, H.M., Di Quinzio, M.K., Permezel, M. and Brennecke, S.P. (2015) Predicting Preterm Labour: Current Status and Future Prospects. Disease Markers, 2015, Article ID: 435014. https://doi.org/10.1155/2015/435014

[19] Esplin, M.S., Elovitz, M.A., Iams, J.D., Parker, C.B., Wapner, R.J., Grobman, W.A., Simhan, H.N., Wing, D.A., Haas, D.M., Silver, R.M., Hoffman, M.K., Peaceman, A.M., Caritis, S.N., Parry, S., Wadhwa, P., Foroud, T., Mercer, B.M., Hunter, S.M., Saade, G.R. and Reddy, U.M. (2017) Predictive Accuracy of Serial Transvaginal Cervical Lengths and Quantitative Vaginal Fetal Fibronectin Levels for Spontaneous Preterm Birth Among Nulliparous Women. The Journal of the American Medical Association, 317, 1047-1056. https://doi.org/10.1001/jama.2017.1373

[20] Woźniak, S., Czuczwar, P., Szkodziak, P., Wrona, W. and Paszkowski, T. (2015) Elastography for Predicting Preterm Delivery in Patients with Short Cervical Length at 18-22 Weeks of Gestation: A Prospective Observational Study. Ginekologia Polska, 86, 442-447. https://doi.org/10.17772/gp/2401

[21] Sabiani, L., Haumonte, J.B., Loundou, A., Caro, A.S., Brunet, J., Cocallemen, J.F., D'ercole, C. and Bretelle, F. (2015) Cervical HI-RTE Elastography and Pregnancy Outcome: A Prospective Study. European Journal of Obstetrics and Gynecology, 186, 80-84. https://doi.org/10.1016/j.ejogrb.2015.01.016

[22] Öcal, F.D., Çekmez, Y., Erdoğdu, E., Gezer, M., Fanuscu, İ., Özkan, H., Kara, O.F. and Küçüközkan, T. (2015) The Utility of Cervical Elastosonography in Prediction of Cervical Insufficiency: Cervical Elastosonography and Cervical Insufficiency. The Journal of Maternal-Fetal \& Neonatal Medicine, 28, 812-818.

https://doi.org/10.3109/14767058.2014.933801

[23] Hernandez-Andrade, E., Garcia, M., Ahn, H., Korzeniewski, S.J., Saker, H., Yeo, L., Chaiworapongsa, T., Hassan, S.S. and Romero, R. (2015) Strain at the Internal Cer- 
vical os Assessed with Quasi-Static Elastography Is Associated with the Risk of Spontaneous Preterm Delivery at $\leq 34$ Weeks of Gestation. Journal of Perinatal Medicine, 43, 657-666. https://doi.org/10.1515/jpm-2014-0382

[24] Swiatkowska-Freund, M., Traczyk-Łoś, A., Preis, K., Łukaszuk, M. and Zielińska, K. (2014) Prognostic Value of Elastography in Predicting Premature Delivery. Ginekologia Polska, 85, 204-207. https://doi.org/10.17772/gp/1714

[25] Köbbing, K., Fruscalzo, A., Hammer, K., Möllers, M., Falkenberg, M., Kwiecien, R., Klockenbusch, W. and Schmitz, R. (2014) Quantitative Elastography of the Uterine Cervix as a Predictor of Preterm Delivery. Journal of Perinatology, 34, 774-780. https://doi.org/10.1038/jp.2014.87

[26] Feltoivch, H., Hall, T.J. and Berghella, V. (2012) Beyond Cervical Length: Emerging Technologies for Assessing the Pregnant Cervix. American Journal of Obstetrics \& Gynecology, 207, 345-354. https://doi.org/10.1016/j.ajog.2012.05.015

[27] Egorov, V., Shobeiri, A.S., Takacs, P., Hoyte, L., Lucente, V. and van Raalte, H. (2018) Biomechanical Mapping of the Female Pelvic Floor: Prolapse versus Normal Conditions. Open Journal of Obstetrics and Gynecology, 8, 900-924. https://doi.org/10.4236/ojog.2018.810093

[28] Egorov, V., van Raalte, H. and Sarvazyan, A. (2010) Vaginal Tactile Imaging. IEEE Transactions on Biomedical Engineering, 57, 1736-1744. https://doi.org/10.1109/TBME.2010.2045757

[29] Gradolewski, D. and Redlarski, G. (2014) Wavelet-Based Denoising Method for Real Phonocardiography Signal Recorded by Mobile Devices in Noisy Environment. Computers in Biology and Medicine, 52, 119-129. https://doi.org/10.1016/j.compbiomed.2014.06.011

[30] Timoshenko, S. and Goodier, J.N. (1951) Theory of Elasticity. McGraw-Hill Book Company, New York, 1-508.

[31] Egorov, V., Tsyuryupa, S., Kanilo, S., Kogit, M. and Sarvazyan, A. (2008) Soft Tissue Elastometer. Medical Engineering \& Physics, 30, 206-212.

[32] Bartlett, J.W. and Frost, C. (2008) Reliability, Repeatability and Reproducibility: Analysis of Measurement Errors in Continuous Variables. Ultrasound in Obstetrics \& Gynecology, 31, 466-475. https://doi.org/10.1002/uog.5256

[33] Bland, J.M. and Altman, D.G. (2003) Applying the Right Statistics: Analyses of Measurement Studies. Ultrasound in Obstetrics \& Gynecology, 22, 85-93. https://doi.org/10.1002/uog.122

[34] Hernandez-Andrade, E., Maymon, E., Luewan, S., Bhatti, G., Mehrmohammadi, M., Erez, O., Pacora, P., Done, B., Hassan, S.S. and Romero, R. (2018) A Soft Cervix, Categorized by Shear-Wave Elastography, in Women with Short or with Normal Cervical Length at 18-24 Weeks Is Associated with a Higher Prevalence of Spontaneous Preterm Delivery. Journal of Perinatal Medicine, 46, 489-501. https://doi.org/10.1515/jpm-2018-0062

[35] Oturina, V., Hammer, K., Möllers, M., Braun, J., Falkenberg, M.K., de Murcia, K.O., Möllmann, U., Eveslage, M., Fruscalzo, A., Klockenbusch, W. and Schmitz, R. (2017) Assessment of Cervical Elastography Strain Pattern and Its Association with Preterm Birth. Journal of Perinatal Medicine, 45, 925-932. https://doi.org/10.1515/jpm-2016-0375

[36] Agarwal, S., Agarwal, A., Joon, P., Saraswat, S. and Chandak, S. (2018) Fetal Adrenal Gland Biometry and Cervical Elastography as Predictors of Preterm Birth: A Comparative Study. Ultrasound, 26, 54-62. https://doi.org/10.1177/1742271X17748515 
[37] Agarwal, A., Chandak, S. and Agarwal, S. (2018) Role of Acoustic Radiation Force Impulse and Shear Wave Velocity in Prediction of Preterm Birth: A Prospective Study. Acta Radiologica, 59, 755-762. https://doi.org/10.1177/0284185117730689

[38] Muller, M., Aït-Belkacem, D., Hessabi, M., Gennisson, J.L., Grangé, G., Goffinet, F., Lecarpentier, E., Cabrol, D., Tanter, M. and Tsatsaris, V. (2015) Assessment of the Cervix in Pregnant Women Using Shear Wave Elastography: A Feasibility Study. Ultrasound in Medicine \& Biology, 41, 2789-2797. https://doi.org/10.1016/j.ultrasmedbio.2015.06.020

[39] Maurer, M.M., Badir, S., Pensalfini, M., Bajka, M., Abitabile, P., Zimmermann, R. and Mazza, E. (2015) Challenging the in-Vivo Assessment of Biomechanical Properties of the Uterine Cervix: A Critical Analysis of Ultrasound Based Quasi-Static Procedures. Journal of Biomechanics, 48, 1541-1548.

https://doi.org/10.1016/j.jbiomech.2015.02.038

[40] Sarvazyan, A., Hall, T.J., Urban, M.W., Fatemi, M., Aglyamov, S.R. and Garra, B.S. (2011) An Overview of Elastography-An Emerging Branch of Medical Imaging. Current Medical Imaging Reviews, 7, 255-282. https://doi.org/10.2174/157340511798038684

[41] Fruscalzo, A., Mazza, E., Feltovich, H. and Schmitz, R. (2016) Cervical Elastography during Pregnancy: A Critical Review of Current Approaches with a Focus on Controversies and Limitations. Journal of Medical Ultrasonics, 43, 493-504. https://doi.org/10.1007/s10396-016-0723-Z

[42] Hernandez-Andrade, E., Aurioles-Garibay, A., Garcia, M., Korzeniewski, S.J., Schwartz, A.G., Ahn, H., Martinez-Varea, A., Yeo, L., Chaiworapongsa, T., Hassan, S.S. and Romero, R. (2014) Effect of Depth on Shear-Wave Elastography Estimated in the Internal and External Cervical os during Pregnancy. Journal of Perinatal Medicine, 42, 549-557. https://doi.org/10.1515/jpm-2014-0073

[43] Dekker, G.A., Lee, S.Y., North, R.A., McCowan, L.M., Simpson, A.B. and Roberts, C.T. (2012) Risk Factors for Preterm Birth in an International Prospective Cohort of Nulliparous Women. PLOS ONE, 7, e39154. https://doi.org/10.1371/journal.pone.0039154

[44] Greco, E., Gupta, R., Syngelaki, A., Poon, L.C.Y. and Nicolaides, K.H. (2012) First-Trimester Screening for Spontaneous Preterm Delivery with Maternal Characteristics and Cervical Length. Fetal Diagnosis and Therapy, 31, 154-161. https://doi.org/10.1159/000335686

[45] Mercer, B.M., Goldenberg, R.L., Moawad, A.H., Meis, P.J., Iams, J.D., Das, A.F., Caritis, S.N., Miodovnik, M., Menard, M.K., Thurnau, G.R., Dombrowski, M.P., Roberts, J.M. and McNellis, D. (1999) The Preterm Prediction Study: Effect of Gestational Age and Cause of Preterm Birth on Subsequent Obstetric Outcome. American Journal of Obstetrics \& Gynecology, 181, 1216-1221. https://doi.org/10.1016/S0002-9378(99)70111-0

[46] Imai, M., Tani, A., Saito, M., Saito, K., Amano, K. and Nisijima, M. (2001) Significance of Fetal Fibronectin and Cytokine Measurement in the Cervicovaginal Secretions of Women at Term in Predicting Term Labor and Post-Term Pregnancy. European Journal of Obstetrics Gynecology and Reproductive Biology, 97, 53-58. https://doi.org/10.1016/S0301-2115(00)00483-8

[47] Goldenberg, R.L., Goepfert, A.R. and Ramsey, P.S. (2005) Biochemical Markers for the Prediction of Preterm Birth. American Journal of Obstetrics and Gynecology, 192, S36-S46. https://doi.org/10.1016/j.ajog.2005.02.015

[48] Honest, H., Forbes, C.A., Durée, K.H., Norman, G., Duffy, S.B., Tsourapas, A., Roberts, T.E., Barton, P.M., Jowett, S.M., Hyde, C.J. and Khan, K.S. (2009) Screening 
to Prevent Spontaneous Preterm Birth: Systematic Reviews of Accuracy and Effectiveness Literature with Economic Modelling. Health Technology Assessment, 13, 1-627. https://doi.org/10.3310/hta13430

[49] Shankar, R., Johnson, M.P., Williamson, N.A., Cullinane, F., Purcell, A.W., Moses, E.K. and Brennecke, S.P. (2010) Molecular Markers of Preterm Labor in the Choriodecidua. Reproductive Sciences, 17, 297-310.

https://doi.org/10.1177/1933719109353454

[50] Kacerovsky, M., Lenco, J., Musilova, I., Tambor, V., Lamont, R., Torloni, M.R. and Menon, R. (2014) Proteomic Biomarkers for Spontaneous Preterm Birth: A Systematic Review of the Literature. Reproductive Sciences, 21, 283-295. https://doi.org/10.1177/1933719113503415

[51] Iams, J.D., Goldenberg, R.L., Meis, P.J., Mercer, B.M., Moawad, A., Das, A., Thom, E., McNellis, D., Copper, R.L., Johnson, F., Roberts, J.M. and National Institute of Child Health and Human Development Maternal Fetal Medicine Unit Network (1996) The Length of the Cervix and the Risk of Spontaneous Premature Delivery. The New England Journal of Medicine, 334, 567-572. https://doi.org/10.1056/NEJM199602293340904

[52] Li, Q., Reeves, M., Owen, J. and Keith, L.G. (2012) Precocious Cervical Ripening as a Screening Target to Predict Spontaneous Preterm Delivery among Asymptomatic Singleton Pregnancies: A Systematic Review. American Journal of Obstetrics \& Gynecology, 212, 145-156. https://doi.org/10.1016/j.ajog.2014.07.003

[53] Myers, K.M., Paskaleva, A.P., House, M. and Socrate, S. (2008) Mechanical and Biochemical Properties of Human Cervical Tissue. Acta Biomaterialia, 4, 104-116. https://doi.org/10.1016/j.actbio.2007.04.009 